\title{
II Coloquio de Estudios Históricos del siglo XX: «Identidad, cultura y política en las revistas del Perú Contemporáneo»
}

Lima, 17 al 19 de septiembre de 2014

\section{Guillermo Fernández Ramos}

\section{(2) OpenEdition}

12 Journals

\section{Edición electrónica}

URL: http://journals.openedition.org/bifea/6010

DOI: $10.4000 /$ bifea.6010

ISSN: 2076-5827

Editor

Institut Français d'Études Andines

\section{Edición impresa}

Fecha de publicación: 1 diciembre 2014

Paginación: 650-654

ISSN: 0303-7495

\section{Referencia electrónica}

Guillermo Fernández Ramos, « II Coloquio de Estudios Históricos del siglo XX: «ldentidad, cultura y política en las revistas del Perú Contemporáneo» », Bulletin de l'Institut français d'études andines [En línea], 43 (3) | 2014, Publicado el 08 diciembre 2014, consultado el 07 noviembre 2020. URL : http:// journals.openedition.org/bifea/6010; DOI : https://doi.org/10.4000/bifea.6010

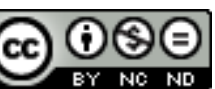

Les contenus du Bulletin de l'Institut français d'études andines sont mis à disposition selon les termes de la licence Creative Commons Attribution - Pas d'Utilisation Commerciale - Pas de Modification 4.0 International. 


\section{COLOQUIO DE ESTUDIOS HISTÓRICOS DEL SIGLO XX: «IDENTIDAD, CULTURA Y POLÍTICA EN LAS REVISTAS DEL PERÚ CONTEMPORÁNEO»}

Lima, 17 al 19 de septiembre de 2014

Entre el miércoles 17 y el viernes 19 de septiembre de 2014, se llevó a cabo en la Casa Museo José Carlos Mariátegui el «ll Coloquio de Estudios Históricos del Siglo XX "Identidad, Cultura y Política en las revistas del Perú Contemporáneo"». El evento fue organizado por el Grupo de Trabajo Historia del Siglo XX (integrado por egresados y estudiantes de Historia de la Universidad Nacional Mayor de San Marcos) y fue auspiciado por el Instituto Francés de Estudios Andinos, la Casa Museo José Carlos Mariátegui y Editorial Horizonte. En esta oportunidad el evento fue coordinado por los historiadores Guillermo Fernández, Nadia López y Melyssa Vergaray. Asimismo, se contó con el apoyo de los estudiantes Lorenzo Huamaní, Ángela Quispe, Joel Segura, Víctor Espinal y Valeria Rosas.

Esta actividad científica permitió reunir a 28 conferencistas agrupados en una lección inaugural y nueve mesas: Itinerarios de las Ciencias Sociales en el Perú, Ideas y proyectos educativos, Intelectuales y revistas, Universidad y Sociedad, Ideología y representaciones políticas, Actores y movimientos sociales, Música y política, Producir Historia en el Perú e Ideología y representaciones políticas durante el Oncenio. A su vez, hubo la oportunidad de presentar dos publicaciones recientes: El pensamiento filosófico de Pedro Zulen de la filósofa Saby Lazarte y Apostilla, revista del Grupo de Trabajo Historia del Siglo XX. Obviamente, no se puede comentar todas las mesas desarrolladas en el evento. Solo resaltaré cinco enseñanzas científicas significativas, entre otras.

La primera versa sobre la importancia de la temática central del evento. Nuestra actual historiografía dominante tiene varios puntos débiles, uno de ellos tiene que ver con el poco interés hacia nuestro siglo XX. Para evidenciar ello basta revisar la lista de eventos académicos que impulsa año tras año. Estos tienen temas similares pues normalmente se aborda el periodo de las Cortes de Cádiz, la Independencia 
peruana o la Guerra contra Chile. Esto es reprochable tomando en cuenta que el siglo XX sí es investigado por nuestros jóvenes historiadores; muestra de ello son las tesis que se presentan en nuestras universidades (Universidad Nacional Mayor de San Marcos, Pontificia Universidad Católica del Perú, Universidad Nacional Federico Villarreal, Universidad Nacional de San Antonio de Abad, Universidad Nacional de Trujillo y la Universidad Nacional de San Agustín).

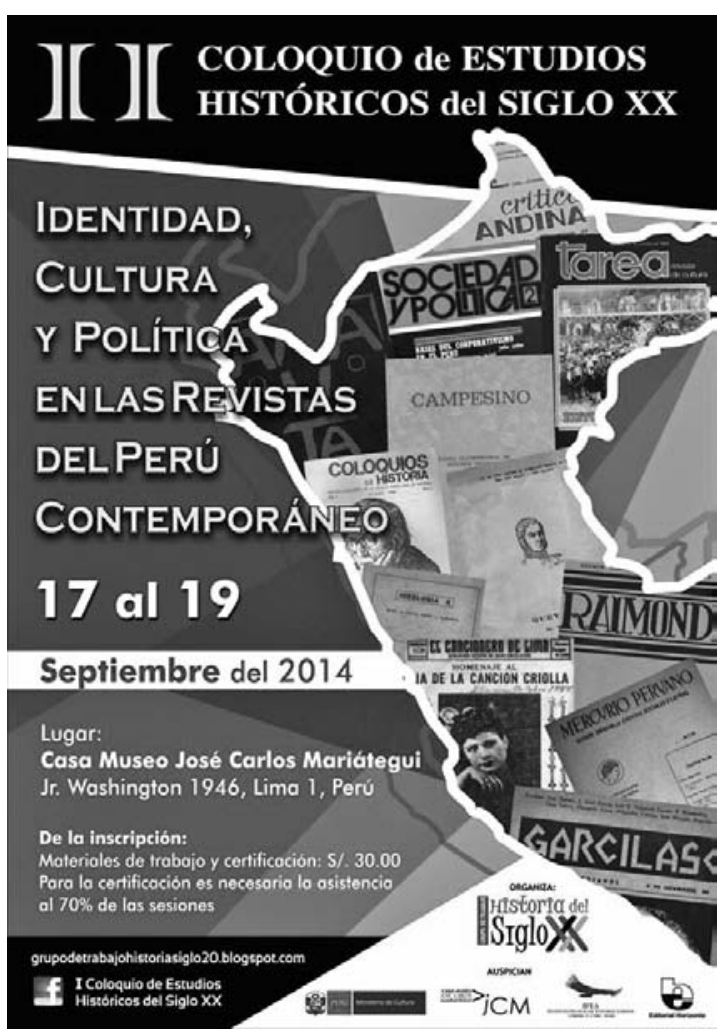

Si ya son escasos los eventos donde se pueda dialogar sobre nuestra historia contemporánea, son aún más escasos los eventos dedicados a las revistas del siglo XX. Solo podemos mencionar como referencia los congresos Internacionales sobre el siglo XIX peruano organizados en el año $2008^{1}$ (Universos discursivos y visuales en la prensa peruana del siglo XIX) y 2013 (Prensa, narraciones e imágenes en América Latina). Debemos de salir de nuestro marco nacional para encontrar algunos modelos de eventos científicos similares. Al respecto, en el año 1990 en la Université de Paris IIISorbonne Nouvelle se realizó el Coloquio Internacional «Le discours culturel dans les revues latino-américaines de 1940 à 1970» y en 1999 se editó el libro La cultura de un siglo. América Latina en sus revistas (1999) producto de un encuentro a propósito del veinticinco aniversario de la revista Hispanoamericana. Estos eventos han abordado la problemática de las revistas en las historias nacionales de los países de América Latina pues a través de sus páginas se han manifestado los principales círculos de avanzada política, social y cultural de cada país2. En el caso del coloquio se presentaron investigaciones que abordaron las revistas de manera individual y colectiva. Las exposiciones versaron sobre revistas como La Escuela Moderna (1911-1915), El Deber ProIndígena (1912-1917), Inca (1923-1925), Boletín Bibliográfico de la Universidad San Marcos (1923-1967), Amauta (1926-1930), Chirapu (1928), Concordia (19281929), La Lira Limeña (1929-1932), Cunan (1931-1932), Revista de la Universidad Católica (1933-1945), Palabra (1936-1944), Boletín del Instituto Psicopedagógico Nacional (1942-1953), Fénix (1943-1948), Campesino (1969-1977), Allpanchis (1969-2010), Histórica (1977-2014), Despertar (1977), Campesinos en Acción

1 Producto de este coloquio Marcel Velásquez editó el libro La República de papel (2009).

2 En algunos casos, como en el de Amauta, las revistas llegaron a trascender los marcos nacionales. 
(1979-1980), Márgenes (1980-2000), Sequilao (1992-2005) y Nueva Corónica (2012-2013).

La segunda enseñanza versa sobre la ruptura del marco cronológico de nuestra historiografía sobre el siglo XX pues todavía se sigue investigando este siglo solo hasta fines de los años veinte como menciona Carlos Aguirre:

El periodo posterior a 1930 clama a gritos mayor atención de la recibida hasta ahora. Lo poco que sabemos se limita a algunos movimientos sociales (obreros y campesinos) y partidos políticos, pero aún en estos terrenos hay una urgente necesidad de traspasar la barrera de 1930 y entrar a analizar las décadas finales del orden oligárquico y, por qué no, los gobiernos posteriores a 1968 (Aguirre, 2002: 478).

Era pues una necesidad romper esta barrera para trabajar el marco cronológico de 1930 a 1980, esto tomando en cuenta que las últimas décadas del siglo XX sí han sido abordadas por nuestros historiadores (Ragas, 2013). Al respecto, se presentaron trabajos que cubren esta cronología como el de Alejandro Estenós (Universidad Católica San Pablo) y Fernando Valle (Universidad Católica San Pablo) sobre la revista Allpanchis (1969-2010) donde se presentó una periodificación de sus etapas. Por su parte, Alberto Loza abordó el Boletín Bibliográfico de la Universidad San Marcos (1923-1967) relacionando su historia con la evolución de la institución que lo impulsó y con sus directores (Pedro Zulen, Jorge Basadre y Federico Schwab). Mientras que Liliana Regalado (Pontificia Universidad Católica del Perú) comparó la evolución de la Revista Histórica (publicación de la Academia Nacional de Historia) e Histórica (publicación de la Pontificia Universidad Católica del Perú). Por otro lado, Carlos Cerquin y Juan Hidalgo (Universidad Nacional Mayor de San Marcos) abordaron el tema de los cancioneros y su filiación política (aprista y sanchecerrista) en el contexto del régimen de Luis Sánchez Cerro. Víctor Samuel Rivera revisó los discursos ideológicos en la Revista de la Universidad Católica (1933-1945) en torno a la II Guerra Mundial. Talía Tauro (Universidad Ricardo Palma) abordó la propuesta cultural en la revista Palabra (1936-1944). Melyssa Vergaray (Universidad Nacional Mayor de San Marcos) revisó la revista Fénix (1943-1948) en la coyuntura del incendio de la Biblioteca Nacional del Perú y Aurora de la Vega (Pontificia Universidad Católica del Perú) analizó el Boletín del Instituto Psicopedagógico Nacional (1942-1953).

Pero los clásicos temas tampoco fueron dejados de lado. Por ejemplo, para el estudio de la revista Amauta se presentaron las ponencias de Ernesto Toledo (Universidad Peruana de Ciencias e Informática) y Sara Beatriz Guardia (Universidad de San Martín de Porres). Sobre las revistas Variedades y Mundial se presentó una investigación de José Chaupis (Universidad Nacional Mayor de San Marcos). Asimismo, se presentaron exposiciones sobre revistas aparentemente «menores» como los trabajos de Nadia López (Universidad Nacional Mayor de San Marcos) sobre la revista La Escuela Moderna (1911-1915), Saby Lazarte (Universidad Ricardo Palma) sobre El Deber Pro-Indígena (1912-1917), Víctor Espinal (Universidad Nacional Mayor de San Marcos) sobre Inca (1923-1925) y Dora Salazar (Universidad Jaime Bausate y Meza) sobre la revista Concordia 
(1928-1929). Sobre estas revistas «menores» es de esperar que estas ponencias sirvan para nuevas investigaciones.

La tercera enseñanza tiene que ver con la evaluación del desarrollo de nuestras disciplinas científicas en el siglo XX. En específico sobre el desarrollo de la Historia en el Perú se dedicaron dos de las mesas del evento: «ltinerarios de las Ciencias Sociales en el Perú» y «Producir Historia en el Perú». En ellas se presentaron trabajos que intentaron realizar algunos balances sobre nuestra disciplina como el de Augusto Lostaunau (Universidad Nacional Federico Villarreal) que estudió la joven historiografía en la Universidad Nacional Federico Villarreal y la producción de sus revistas. Por su parte, Juvenal Luque (Universidad Nacional Mayor de San Marcos) expuso sobre Nueva Corónica y la importancia de las revistas digitales. Asimismo, existieron ponencias de carácter testimonial sobre la producción de revistas hechas por científicos sociales. Sobre ello Sara Rondinel (Pontificia Universidad Católica del Perú) abordó la revista Márgenes (1980-2000), Antonio Rengifo (Universidad Nacional Mayor de San Marcos) expuso sobre la experiencia en la revista Campesino (1969-1977), Antonio Coello (Universidad Nacional Mayor de San Marcos) hizo lo propio con su exposición sobre Sequilao (19922005). A estos trabajos se sumó el de Edilberto Huamaní (Universidad Nacional de Ingeniería) sobre las publicaciones de la Universidad Nacional de Ingeniería, siendo una de las más representativas la revista Amaru.

La cuarta enseñanza tiene que ver con algunos vacíos que este evento no pudo cubrir. Uno de estos fue la parte metodológica. Todas las ponencias partieron de la premisa de las revistas como una fuente imprescindible para entender nuestra historia; sin embargo, no se discutió sobre las revistas como fuente para la historia contemporánea. Solo la exposición inaugural de Gérard Borras (Instituto Francés de Estudios Andinos) trabajó la temática metodológica con su ponencia sobre los cancioneros de Lima y la discusión de si estos son revistas o periódicos o cancioneros. También, resalta el que no se contó con una mayor cantidad de exposiciones sobre revistas regionales. Al respecto, Alejandro Estenós y Fernando Valle expusieron sobre la revista Allpanchis, Mizael Huamaní (Universidad Nacional Mayor de San Marcos) y Juan Tito (Universidad Nacional Mayor de San Marcos) expusieron una introducción al mundo de las revistas campesinas peruanas, Wilfredo Kapsoli (Universidad Ricardo Palma) expuso sobre la revista Chirapu y la vanguardia intelectual arequipeña y Richard Chuhue (Universidad Nacional Mayor de San Marcos) abordó el tema de la revista Cunan. Esta última revista tiene como peculiaridad ser una publicación impulsada por pintores y editarse en más de una región (Cuzco-Arequipa-Puno).

La última enseñanza y con la cual pienso sintetizar el aporte de este evento científico radica en que durante los tres días de desarrollo del coloquio se demostró que la producción intelectual en el Perú no se agotó con los aportes de la generación del Novecientos (José de la Riva-Agüero, Francisco García Calderón y Víctor Andrés Belaunde) y del Centenario (José Carlos Mariátegui, Víctor Raúl Haya de la Torre y Jorge Basadre). En su tiempo existieron otras propuestas intelectuales «marginales» que también merecen ser estudiadas. Asimismo, esa riqueza intelectual no solo se 
redujo a un solo marco cronológico determinado (de 1900 a 1930) ni a una clase social determinada (como lo demuestran las revistas impulsadas por los mismos campesinos).

\section{Referencias citadas}

AGUILAR MORA, J., SOSNOWSKI, S. et al., 1999 - La cultura de un siglo: América Latina en sus revistas, 589 pp.; Madrid: Alinaza Editorial.

AGUIRRE, C., 2002 - La historia social del Perú republicano (1821-1930). Histórica (Lima), XXVI, 2: 445-501.

RAGAS, J., 2013 - Los historiadores y el informe final de la Comisión de la Verdad y Reconciliación (Perú, 2003-2013). Argumentos, 7 (4): 52-59.

VELÁSQUEZ, M. (Ed.), 2009 - La República de papel. Política e imaginación social en la prensa peruana del siglo XIX, 341 pp.; Lima: Fondo Editorial de la Universidad de Ciencias y Humanidades. 